\title{
ESTUDO DO NÍVEL DE COMPARABILIDADE DOS AJUSTES PARCIAIS EM USGAAP E BRGAAP
}

\author{
SIRLEI LEMES \\ Doutora em Controladoria e Contabilidade \\ Pela Universidade de São Paulo \\ Professora da Universidade Federal de Uberlândia \\ E-mail: sirlemes@uol.com.br
}

LYCEA MARIA MACIEL NOGUEIRA

Graduada em Ciências Contábeis pela

Universidade Federal de Uberlândia

E-mail: lyceamaria@yahoo.com.br

\section{Resumo}

O objetivo do presente trabalho é analisar o nível de comparabilidade das empresas brasileiras que apuram seus resultados de acordo com os USGAAP, por meio da identificação e do tratamento dos principais ajustes no lucro e no patrimônio líquido entre as demonstrações contábeis, de acordo com os dois conjuntos de normas BRGAAP e USGAAP, no período de 2000 a 2006. A pesquisa se desenvolveu nas seguintes etapas: quantificação dos ajustes nas demonstrações contábeis, identificação monetária dos ajustes, apuração do nível de comparabilidade entre os ajustes e entre os lucros divulgados. 0 propósito dos cálculos pontuais (2000 e 2006) foi verificar se houve, ao longo dos 7 anos, aproximação nos números gerados pelas duas normas. 0 estudo se caracteriza como exploratório e, como técnica de coleta de dados, adotou-se a pesquisa documental. A classificação dos ajustes seguiu a realizada por UCIEDA (2003) e o cálculo do nível de comparabilidade dos ajustes se deu por meio do Índice de Comparabilidade de Gray (1980). Identificou-se que os ajustes que mais afetaram as reconciliações analisadas foram: Combinação de Negócios e Intangíveis. Na seqüência, demonstrou-se que as empresas, em sua maior parte, não tiveram seus ajustes comparáveis a $5 \%$ e $10 \%$ de materialidade, apontando para mensurações materialmente diferentes do lucro/prejuízo líquido, apurado segundo os BRGAAP e os USGAAP. 0 estudo se limitou pelos poucos anos de pesquisa, por esta ser documental e, portanto, dependente da confiabilidade das informações divulgadas pelas empresas e, ainda, por não terem sido convertidas as demonstrações de forma completa, considerando que nenhum contato foi estabelecido com as empresas.

Palavras-chave: BRGAAP; USGAAP; reconciliação; comparabilidade.

\section{Abstract}

The objective of this study is to analyze the level of comparability of Brazilian companies that report their results in accordance with USGAAP through the identification and evaluation of the principal adjustments to profit and liquid assets from accounting reports (2000 to 2006) in accordance with the two sets of standards: BRGAAP and USGAAP. The research was developed through the following steps: quantification of the adjustments from the accounting reports, summarizing the adjustments in table form and determining the level of comparability between adjustments and between reported profits. Calculations were made at two points (2000 and 2006) to determine if the numbers generated by the two standards had converged during that seven year period. This study is characterized as exploratory and data collection was from document research. Classification of adjustments followed those of UCIEDA (2003) and the level of comparability of the adjustments was calculated using the Gray Comparability Index (1980). It was shown that the adjustments that had the greatest effect on the reconciliations analyzed were Business Combination and Intangibles. Additionally, it was demonstrated that the majority of companies did not have adjustments comparable to $5 \%$ and $10 \%$ materiality indicating significantly different measurements of liquid profit/loss determined by BRGAAP and USGAAP. This study was limited by the number of years researched, because research was from documents and therefore dependent on the reliability of the information disclosed by the companies and also for incomplete conversion of the accounting reports because contact was not established with the companies.

Key words: BRGAAP, USGAAP, reconciliations, comparability. 


\section{INTRODUÇÃO}

Diante da dinamização do mercado mundial, da abertura dos mercados e da internacionalização de capitais, tem sido maior o número de empresas que necessitam de recursos, em países desenvolvidos, via emissão de American Depositary Receipts (ADRs) ${ }^{1}$. Por outro lado, ainda se identificam grandes divergências entre as normas contábeis brasileiras e aquelas emitidas pelo FASB, órgão norte-americano responsável pela aprovação e divulgação de normas contábeis daquele país, os USGAAP (United States Generally Accounting Accepted Principle). No mercado global, tanto os investidores pessoas físicas quanto jurídicas buscam oportunidades de investimentos internacionais. Contudo, as significativas divergências entre as normas contábeis utilizadas pelas empresas nos diferentes países dificultam a comparação do seu desempenho financeiro e econômico, prejudicando a decisão dos investidores. Segundo Lopes e Martins (2005, p.32), “[...] a própria existência da contabilidade está ligada à existência de problemas de informação". Assim, torna-se necessário o estudo das demonstrações contábeis de acordo com as Normas Contábeis Norte Americanas, os USGAAP, e as demonstrações contábeis de acordo com a norma contábil brasileira, no sentido de identificar as principais divergências entre os dois conjuntos de normas. Enquanto o país não avança no processo de modernização e de convergência das normas contábeis, cabe às empresas brasileiras que pretendem aumentar sua capacidade de alavancagem operacional ou competitividade e eficiência, por meio da redução dos custos de captação, divulgar voluntariamente informações preparadas segundo as normas internacionais de contabilidade (PRICEWATERHOUSECOOPERS, 2004).

Apesar dos avanços obtidos, principalmente com a aprovação de pronunciamentos da CVM e de mudanças introduzidas na Lei 6.404/76, as diferenças existentes entre a norma contábil brasileira e a norma contábil norte-americana ainda são grandes e, com freqüência, algumas empresas acabam tendo de justificar ao investidor norte-americano o porquê das alterações do lucro ou do prejuízo apurado pelas empresas ou, até mesmo, o porquê de a empresa apresentar lucro no Brasil e prejuízo nos EUA ou vice-versa. Nesse sentido, as pesquisas precisam avançar a fim de investigar de que forma as divergências entre as normas contábeis, em nível internacional, podem impactar os indicadores de desempenho das organizações.

Diante de uma realidade enfrentada pelas empresas transnacionais, após os escândalos financeiros recentes ocorridos pelo mundo, o FASB passou a participar mais efetivamente do processo de emissão de um conjunto único de normas contábeis: as ditas Normas de Contabilidade Internacional (IFRS/IAS) ${ }^{2}$, emitidas pelo IASB ${ }^{3}$. Devido tanto às críticas quanto à pouca participação dos EUA no projeto de convergência de normas contábeis para uma norma internacional, o FASB assinou, em 2002, um acordo comprometendo-se a ter suas normas ajustadas com as Normas Internacionais. Os termos do acordo prevêem que até 2008 sejam ajustadas as diferenças entre os USGAAP e os IFRS/IAS e que, para 2009, a SEC (órgão similar a CVM brasileira), responsável pela

\footnotetext{
1 ADR (American Depositary Receipts) são títulos representativos das ações de companhias brasileiras transacionados nas bolsas de valores norte-americanas.

2 As IAS (International Accounting Standards) era o título dos documentos emitidos pelo IASB até 2000. A partir de então o IASB passou a emitir suas normas com a sigla IFRS (International Financial Reporting Standards).

${ }^{3}$ IASB e o órgão internacional, criado em 1973 com o nome de IASC (International Accounting Standards Committee), com o objetivo de harmonizar as normas contábeis entre todos os países e que tem tido sucessos efetivos de seu propósito, no sentido de identificar as principais divergências entre os dois conjuntos de normas.
} 
fiscalização do mercado de capitais norte-americano, vá aceitar que empresas estrangeiras apresentem as demonstrações financeiras seguindo as IFRS/IAS.

O mercado de capitais exige informações comparáveis que facilitem as transações entre países. Daí a necessidade de analisar as variações entre os valores gerados pelas empresas, visando dar suporte a um processo que ocorre em nível internacional de busca por uma contabilidade harmonizada internacionalmente.

As empresas brasileiras, em sua maioria, ainda não estão obrigadas a publicar suas demonstrações contábeis em IFRS/IAS, nem tampouco de acordo com os USGAAP. Excluemse dessa não obrigatoriedade aquelas que aderiram ao Novo Mercado da BOVESPA e também as que captam recursos, via ADR, no mercado norte-americano. Ressalta-se que a assimetria de informações, provocada por diferenças entre as normas contábeis entre os países, pode prejudicar as decisões de investidores, ou, no mínimo, caracterizar-se como mais uma dificuldade para tais usuários.

De forma mais efetiva, a Lei 11638/07, que alterou dispositivos da Lei 6404/76, determinou que os pronunciamentos da CVM sejam emitidos de acordo com as Normas Internacionais aprovadas pelo IASB. Antes disso, em 2007, a CVM já havia determinado que as companhias abertas publicassem as demonstrações consolidadas, a partir de 2010, seguindo a Norma Internacional.

Nesse sentido, o objetivo deste trabalho é analisar o nível de comparabilidade das empresas brasileiras que apuram seus resultados de acordo com os USGAAP, por meio da identificação e da análise das principais diferenças existentes entre as demonstrações contábeis emitidas segundo os dois conjuntos de normas: BRGAAP e USGAAP.

De forma específica, este trabalho apresenta:

- Revisão bibliográfica sobre a convergência das normas contábeis;

- Identificação, em termos quantitativos e monetários, dos ajustes de BRGAAP para USGAAP de 2000 a 2006;

Estudo das diferenças dos ajustes parciais entre as demonstrações contábeis em USGAAP e BRGAAP, usando o índice de comparabilidade de Gray.

\section{CONVERGÊNCIA DAS NORMAS CONTÁBEIS}

Um marco importante para a harmonização da contabilidade foi a criação do IASC. O IASC teve sua estrutura concebida no Congresso Mundial de Contadores realizado em Sidney, em 1972. Em 1973, entrou em atividade, sendo sediado em Londres.

O IASC era um setor independente, confidencial, cujo objetivo era facilitar o fluxo de capital, orientando para a elaboração de demonstrações financeiras mais comparáveis, mesmo que preparadas sob diferentes normas de contabilidade. Segundo Haverty (2006), o IASC escolheu a estratégia de permitir uma variação de métodos contábeis. A evidenciação da prática foi enfatizada em vez de forçar a conformidade com um modelo contábil particular. Esta estratégia assegurou a sustentação internacional passiva do IASC com os mercados financeiros do mundo. Entretanto, com o passar dos anos e em função de críticas recebidas, o IASC reduziu, gradualmente, o número de normas alternativas de contabilidade.

Desde 1973, o IASC e sua organização emitiram 41 normas de contabilidade sob a sigla IAS (International Accounting Standard) e oito foram emitidas em anos mais recentes, como IFRS. Das 41 normas emitidas como IAS, apenas 29 estão em vigor, totalizando 37 
pronunciamentos como IAS ou IFRS, aprovados até janeiro de 2008. Em 2001, foi criado, com base na estrutura do IASC, O IASB (International Accounting Standards Board), assumindo as responsabilidades técnicas do IASC a partir dessa data. A criação do IASB teve por objetivo, além de segregar as funções de gerenciamento e de emissão de normas, melhorar os Pronunciamentos Contábeis Internacionais anteriores, emitidos pelo IASC. 0 IASB não tem autoridade para reforçar a conformidade com essas normas, mas muitos países permitiram ou incentivaram o uso das IFRS, como alternativa ou suplemento das suas próprias normas nacionais de contabilidade. Bélgica, França e Itália, por exemplo, permitiram que as IFRS fossem usadas para fins de relatórios financeiros domésticos.

O desenvolvimento de uma linguagem financeira única, aceita em todas as partes do mercado mundial, é uma realidade cada vez mais próxima para o IASB. A adoção das IFRS pelas empresas dos países da União Européia e decisões semelhantes, pela Austrália, por Hong Kong e pela África do Sul mostraram o caminho para um processo que resultou em mais de 100 países que adotam e/ou permitem o uso das IFRS.

Segundo Haverty (2006), a convergência contábil busca obter um estado de harmonização da contabilidade. Com uma economia globalizada, as informações contábeis das empresas são analisadas por diferentes investidores, nos mais diversos locais do mundo. Minimizar ou eliminar essas diferenças pode ajudar os investidores na análise das informações, em qualquer mercado em que a empresa estiver negociando suas ações. Com isso, cresce, a cada dia, a necessidade de um sistema de demonstrações contábeis melhoradas e homogeneizadas.

O Brasil iniciou o processo de convergência das normas brasileiras aos padrões internacionais do IASB e, em 2006, um importante passo foi dado nesse sentido com a criação do Comitê de Pronunciamentos Contábeis (CPC). Formado por representantes da Associação Brasileira das Companhias Abertas (ABRASCA), da Associação dos Analistas e Profissionais de Investimento do Mercado de Capitais (APIMEC NACIONAL), da Bolsa de Valores de São Paulo (BOVESPA), do Conselho Federal de Contabilidade (CFC), da Fundação Instituto dos Auditores Independentes do Brasil (IBRACON), o objetivo principal do CPC é, exatamente, promover discussões buscando o alinhamento das normas nacionais às internacionais.

O CPC é totalmente autônomo das entidades representadas, deliberando por $2 / 3$ de seus membros, e estes, dois por entidade, na maioria contadores, não auferem remuneração. 0 Conselho Federal de Contabilidade fornece a estrutura necessária. Além dos 12 membros atuais, serão sempre convidados a participar representantes do Banco Central do Brasil, da Comissão de Valores Mobiliários (CVM), da Secretaria da Receita Federal e da Superintendência de Seguros Privados (SUSEP). Outras entidades ou especialistas poderão ser convidados, formando comissões e grupos de trabalho para temas específicos.

Diante o processo de convergência já iniciado, o caminho ainda é longo. Conforme Carvalho, Lemes e Costa (2006, p.11) "o caminho para a contabilidade internacional tem pedágios. Um deles é quebrarmos este perigoso paradigma: o de que um balanço interessa primariamente ao Fisco e é a ele que toda a atenção deve ser dada."

Um passo significativo, no sentido da convergência da contabilidade brasileira com as normas internacionais, foi a sanção da Lei 11.638 em dezembro de 2007. Essa Lei altera dispositivos da Lei 6.404/76 e aproxima, em vários itens, as práticas brasileiras das previstas na Norma Internacional, apesar de permanecerem diferenças significativas entre ambas as legislações.

A CVM confirmou que, a partir de 2010, as companhias abertas adotarão, obrigatoriamente, as normas internacionais definidas pelo IASB em suas demonstrações contábeis financeiras consolidadas. Outros países, como Canadá, Índia, Coréia e Japão, 
adotarão as IFRS antes de 2011.

\section{CAUSAS DAS PRÁTICAS CONTÁBEIS DIFERENCIADAS}

Niyama (2005) comenta que, considerando-se que cada país tem seu conjunto de leis, regras, filosofias, procedimentos, objetivos, é razoável supor que os sistemas contábeis de cada país venham a ser impactados por tais medidas, dependendo do seu grau de influência sobre outros.

Um ponto que influencia na diferenciação das normas contábeis é o sistema legal de cada país. Niyama (2005) diz que ele pode ser classificado em duas correntes: commom law e code law. A corrente common law ou direito consuetudinário, de acordo com Lopes e Martins (2005), é praticado em países que fizeram parte do império britânico. Estados Unidos, Canadá, Austrália, Nova Zelândia, Malásia são alguns exemplos, além do próprio Reino Unido. Por sua vez, a corrente code law, ou direito romano, é praticada em países que estiveram sob influência do império romano, inicialmente e, posteriormente, sob influência francesa. França, Alemanha, Itália, Portugal e Espanha são os principais exemplos dessa tradição na Europa. Os países que foram colônias ibéricas na América do Sul adotam, naturalmente, o regime de direito romano. As principais diferenças entre esses dois regimes estão na origem e na força das leis. No direito romano, as normas emanam do texto legal. Isto é, para que algo tenha valor, é necessário que haja uma menção clara e específica na lei. No direito consuetudinário, a origem da regulamentação está mais ligada aos costumes e tradições.

Para Lopes e Martins (2005, p.53),

o processo contábil é afetado em suas três etapas pelo regime legal. Inicialmente, o reconhecimento é influenciado pelo contraste entre a visão econômica e jurídica da contabilidade. Em países de direito romano existe a tendência de, por exemplo, somente ser permitido o reconhecimento de um ativo quando a entidade tiver controle legal sobre este. Nos países de direito consuetudinário, a tradição está mais ligada à essência econômica da relação da empresa com o ativo do que sua formalização legal.

Outros pontosque influenciam nas práticas contábeis diferenciadas, de acordo com Castro Neto (1998), são: a formação histórica de cada país; a influência cultural recebida; o nível de controle governamental, dentre outras. Além disso, pode-se citar as características dos contadores, ou seja, o sistema de educação profissional dos contadores; status, idade e tamanho da profissão contábil.

Segundo Niyama (2005 p.28),

nos países onde o mercado de capitais é sólido e atuante, como Canadá, Estados Unidos, Grã-bretanha, informações financeiras confiáveis e tempestivas têm sido requeridas pelos seus usuários (investidores de forma geral). A profissão contábil nesses países é "auto-regulamentada" (com pouca influência do governo) e é responsável pela promulgação de padrões contábeis e de auditoria. Também é a própria profissão contábil que estabelece critérios para o credenciamento de contadores e auditores, por meio de seus conselhos ou órgãos de classe, seja por meio de exames ou certificações.

O status da profissão contábil influencia as demonstrações contábeis de forma geral. No entanto, no Brasil, a capacidade de influência não é a esperada. Portanto, pode-se dizer que países com status elevados possuem maior qualidade nas demonstrações contábeis, aumentando a confiabilidade das mesmas perante os usuários da 
informação contábil.

\title{
4 METODOLOGIA DO ESTUDO
}

Considerando o objetivo deste trabalho de identificar as principais diferenças nas práticas contábeis das empresas brasileiras que adotaram os USGAAP, no período de 2000 a 2006, o trabalho caracteriza-se como exploratório, conforme a classificação de Gil (2002). Como técnica de coleta de dados, adotou-se a pesquisa documental, que se diferencia da pesquisa bibliográfica da seguinte forma:

\begin{abstract}
A pesquisa documental se assemelha à pesquisa bibliográfica, todavia não levanta material editado - livros, periódicos etc. -, mas busca material que não foi editado, como cartas, memorandos, correspondências de outros tipos, avisos, agendas, propostas, relatórios, estudos, avaliações etc. (Martins e Theóphilo, 2007, p. 85).
\end{abstract}

No Quadro 1, a seguir, são apresentadas as 28 empresas que emitiram ADR em 2006 e para as quais as respectivas demonstrações contábeis e as reconciliações do lucro e do patrimônio líquido em USGAAP e BRGAAP estão disponíveis. Destas, somente 9 empresas apresentaram a reconciliação dos valores no período do estudo.

\begin{tabular}{l|r|l|r|}
\hline EMPRESAS & Lucro Líq BRGAAP 2006 & EMPRESAS & Lucro Líq BRGAAP 2006 \\
\hline AMBEV & $2.806,30$ & GERDAU & $2.880,90$ \\
\hline ARACRUZ & $1.148,30$ & PERDIGÃO & 117,30 \\
\hline BCO BRADESCO & $5.054,00$ & PETROBRÁS & $25.918,90$ \\
\hline BCO ITAÚ & $4.308,90$ & SABESP & 778,90 \\
\hline BR TELECOM & $432.391,00$ & SADIA & 375,50 \\
\hline BR TELECOM PART & $470.368,00$ & TELEMIG & 113,40 \\
\hline BRASKEM & 101,30 & TELE NORTE & $-76,10$ \\
\hline CBD & 85,60 & TELE NORTE LESTE & 1,30 \\
\hline CEMIG & $1.718,80$ & TELESP & $2.816,00$ \\
\hline COPEL & $1.243,00$ & TIM PART & $-301,70$ \\
\hline CSN & $1.167,50$ & ULTRAPAR & 282,10 \\
\hline CVRD & $13.431,00$ & UNIBANCO & $1.750,00$ \\
\hline EMBRAER & 621,70 & VIVO PART & 16,30 \\
\hline GOL & $684.472,00$ & VOTORANTIM & 655,80
\end{tabular}

Quadro 1- Amostra da pesquisa

Para o estudo do efeito das diferenças nos números divulgados pelas empresas, foi utilizado o Índice de Comparabilidade de Gray. 0 índice foi, inicialmente, desenvolvido por Gray (1980) e pode ser identificado para este trabalho como:

Índice de comparabilidade =1 ( $\underline{\text { Lucro Líquido USGAAP }- \text { Lucro Líquido }}$ BRGAAP)

| Lucro LíquidousGaAP | 
Quando o resultado da Equação 1 for igual a 1, tem-se neutralidade. Quando o resultado for maior do que 1 , o lucro relatado no Brasil é maior do que aquele relatado sob os USGAAP e, quando o resultado for menor do que 1, o lucro relatado no Brasil é menor do que aquele relatado sob os USGAAP.

Haverty (2006) calculou o índice para o lucro líquido e para o patrimônio líquido (PL) de empresas chinesas que também reportam em USGAAP e concluiu que, apesar do movimento no sentido da harmonização e convergência, as companhias chinesas mostraram diferenças significativas apresentando o lucro líquido e o PL em USGAAP. Essas diferenças se deveram, principalmente, à prática de reavaliação de ativos fixos, uma vez que as normas contábeis chinesas permitem a reavaliação, enquanto as normas contábeis norte-americanas não o fazem.

Weetman et al. (1998) estudaram as diferenças entre as normas contábeis britânicas e os USGAAP. O estudo compreendeu o período de 1988 a 1994. 0 índice de comparabilidade mostrou que, em 1988, o lucro sob os princípios de contabilidade britânicos representou $16,8 \%$ do lucro sob os USGAAP. Em 1994, essa diferença elevou-se para $25,3 \%$, concluindo que a norma contábil britânica tornou-se menos comparável com os USGAAP.

No sentido de realizar um estudo mais aprofundado das causas das diferenças identificadas, foi utilizado, no presente estudo, o Índice Parcial de Comparabilidade calculado pela seguinte equação:

Índice Parcial de Comparabilidade $=1$ - $\underline{\text { Ajustes Parciais }}$

$$
\mid \text { LLE USGAAP }_{\text {| }}
$$

No caso da Equação 2, tem-se que, para os resultados entre 0,90 e 1,10, os ajustes são considerados materiais a $10 \%$ e, para resultados entre 0,95 e 1,05 , os ajustes são considerados materiais a 5\%. Embora não haja um nível comumente aceito de materialidade, os percentuais aqui adotados (5\% e 10\%) são consistentes com outros estudos (HAVERTY, 2006; ADAMS et al. 1999; GRAY, 1980).

\section{DIFERENÇAS PARCIAIS DAS PRÁTICAS CONTÁBEIS}

Nesta seção, são discutidas as principais práticas contábeis que dão origem a ajustes entre as demonstrações contábeis em BRGAAP e USGAAP. Tais itens se fundamentaram naqueles apresentados por Ucieda (2003), complementados por itens de ajustes evidenciados nas demonstrações analisadas.

1) Ações em Tesouraria: classificação de ações em tesouraria como ativo ou patrimônio líquido.

2) Arrendamento Mercantil: reconhecimento de leasing financeiro e da depreciação de tais itens.

3) Ativos Fixos: reavaliação de ativos, capitalização de despesas de juros, depreciação, impairment de ativos e outros relacionados.

4) Combinação de Negócios: combinação de negócios e aquisição de participações minoritárias. 
5) Consolidação: aplicação do método de equivalência patrimonial, consolidação total e parcial, conversão de demonstrações contábeis e inflação.

6) Correção Monetária: de acordo com os BRGAAP, a contabilização da correção monetária foi descontinuada a partir de $1^{\circ}$ de janeiro de 1996 . No entanto, de acordo com os USGAAP, o Brasil deixou de ser tratado como um país de economia altamente inflacionária somente a partir de $1^{\circ}$ de janeiro de 1998 , gerando diferenças referentes a esse período.

7) Diferenças Cambiais: reconhecimento de ganhos cambiais não realizados e outros relacionados.

8) Dividendos: reconhecimento de dividendos declarados.

9) Goodwill: período de amortização diferente, amortização de goodwill negativo, impairment e demais tratamentos diferenciados para goodwill ${ }^{4}$.

10) Imposto Diferido: reconhecimento de ativos e passivos fiscais diferidos e as mensurações respectivas.

11) Imposto Diferido e Participações Minoritárias: efeitos do imposto de renda e de participações minoritárias sobre os ajustes.

12) Instrumento Financeiro: reconhecimento e mensuração de instrumentos financeiros.

13) Intangível: despesas com lançamento de ações, gastos pré-operacionais, pesquisa e desenvolvimento e outros intangíveis.

14) Investimentos: investimentos em títulos e ações, lucros não realizados, determinados ganhos e prejuízos não realizados dos títulos disponíveis para a venda da companhia, empréstimos para adquirir as próprias ações, provisões e outros.

15) Planos de Pensão: reconhecimento de benefícios de aposentadoria, plano de pensão, plano de pensão complementar e licença-prêmio.

16) Provisão: gastos de reestruturação, contingências e outros relacionados.

17) Outros: tópicos tratados como tais pela própria empresa e os classificados desta forma em função da não identificação com nenhum dos 16 itens identificados.

A Tabela 1 apresenta os ajustes por item, no resultado do exercício, divulgados pelas empresas da amostra no período de 2000 a 2006. A amostra, neste caso, se refere àqueles que apresentaram a reconciliação do lucro e do PL no período, totalizando 9 empresas.

\footnotetext{
${ }^{4}$ Neste estudo, considerou-se, também, para este item, todas as diferenças identificadas pelas empresas como decorrentes de ágio ou deságio, mesmo que estes sejam conceitualmente diferentes de goodwill.
} 
Tabela 1 - $\mathrm{N}^{\circ}$ de Ajustes no LLE de 2000 a 2006 - BRGAAP x USGAAP

\begin{tabular}{|l|c|c|c|c|c|c|c}
\hline Ajuste Lucro Líquido & 2000 & 2001 & 2002 & 2003 & 2004 & 2005 & 2006 \\
\hline Ações em Tesouraria & 1 & 1 & 1 & 1 & 1 & 1 & 1 \\
\hline Arrendamento Mercantil & 1 & - & - & 2 & 3 & 4 & 4 \\
\hline Ativos Fixos & 19 & 20 & 18 & 19 & 25 & 24 & 19 \\
\hline Combinação de Negócios & 9 & 6 & 9 & 13 & 19 & 23 & 21 \\
\hline Consolidação & 5 & 6 & 6 & 8 & 7 & 7 & 7 \\
\hline Correção Monetária & 10 & 11 & 12 & 12 & 13 & 13 & 11 \\
\hline Diferenças Cambiais & 1 & 1 & 1 & 1 & 2 & 2 & 2 \\
\hline Dividendos & - & 2 & 2 & 2 & - & - & - \\
\hline Goodwill & 4 & 6 & 8 & 11 & 15 & 16 & 16 \\
\hline Imposto Diferido e Part. minoritárias & 8 & 9 & 9 & 9 & 10 & 10 & 17 \\
\hline Imposto Diferido & 6 & 4 & 4 & 1 & 2 & 3 & 2 \\
\hline Instrumentos Financeiros & 2 & 4 & 6 & 7 & 8 & 8 & 7 \\
\hline Intangíveis & 7 & 9 & 11 & 15 & 21 & 21 & 24 \\
\hline Investimento & 2 & 3 & 3 & 4 & 6 & 5 & 4 \\
\hline Planos de Pensão & 18 & 19 & 16 & 17 & 19 & 18 & 16 \\
\hline Provisão & 1 & 4 & 4 & 1 & 6 & 5 & 4 \\
\hline Outros & 7 & 9 & 7 & 8 & 7 & 8 & 8 \\
\hline & & & & & & & \\
\hline Total & 101 & 114 & 117 & 131 & 164 & 168 & 163
\end{tabular}

Verifica-se um significativo aumento no número de incidência dos itens "Combinação de Negócios", "Goodwill" e "Intangíveis", ao longo dos sete anos. Destaca-se destes o item "Intangíveis", que teve o maior aumento de incidência, variando em mais de $200 \%$, de 2000 para 2006. Em sentido oposto, o item "Imposto Diferido" apresentou uma gradual redução, representando, em 2006, apenas 33\% da quantidade de ajustes identificados em 2000. O item “Imposto Diferido e Participações Minoritárias" teve um significativo aumento de 2005 para 2006. Os demais itens não tiveram um aumento significativo ao longo dos anos, mantendo-se constantes.

Vale ressaltar que itens como "Ativo Fixo", "Correção Monetária" e "Planos de Pensão" mantiveram-se constantes ao longo do período, salientando-se, contudo, o alto número de observações. O Ativo Fixo, por exemplo, resultou em 20 ajustes em 2001, 25 em 2004 e 24 em 2005. Itens como Ações em Tesouraria e Diferenças Cambiais foram os que menos ajustes produziram no período.

$\mathrm{Na}$ Tabela 2, apresenta-se o total de ajustes ocorridos no Patrimônio Líquido das 9 empresas pesquisadas durante o período de 2000 a 2006. 
Tabela 2 - N de Ajustes no PL de 2000 a 2006 - BRGAAP x USGAAP

\begin{tabular}{|c|c|c|c|c|c|c|c|}
\hline Total Ajuste PL & 2000 & 2001 & 2002 & 2003 & 2004 & 2005 & 2006 \\
\hline Ações em Tesouraria & 1 & 1 & 1 & 1 & 2 & 2 & 2 \\
\hline Arrendamento Mercantil & 1 & 1 & - & 2 & 5 & 4 & 4 \\
\hline Ativos Fixos & 18 & 21 & 23 & 20 & 25 & 26 & 22 \\
\hline Combinação de Negócios & 10 & 11 & 14 & 19 & 28 & 32 & 33 \\
\hline Consolidação & 3 & 3 & 5 & 4 & 6 & 8 & 7 \\
\hline Correção Monetária & 10 & 10 & 13 & 13 & 14 & 13 & 12 \\
\hline Dividendos & 2 & 2 & 1 & 2 & 4 & 3 & 5 \\
\hline Goodwill & 4 & 6 & 11 & 17 & 24 & 18 & 18 \\
\hline Imposto Diferido e Part. Minoritárias & 7 & 8 & 9 & 9 & 10 & 10 & 9 \\
\hline Imposto Diferido & 4 & 6 & 1 & 2 & 4 & 4 & 4 \\
\hline Instrumentos Financeiros & 3 & 5 & 7 & 8 & 8 & 10 & 13 \\
\hline Intangíveis & 4 & 6 & 7 & 10 & 16 & 16 & 15 \\
\hline Investimento & 2 & 3 & 4 & 5 & 7 & 6 & 6 \\
\hline Planos de Pensão & 14 & 23 & 20 & 21 & 22 & 22 & 24 \\
\hline Provisão & 1 & 1 & 2 & 1 & 3 & 4 & 3 \\
\hline Outros & 7 & 9 & 8 & 7 & 8 & 9 & 9 \\
\hline Total & 91 & 116 & 126 & 141 & 186 & 187 & 186 \\
\hline
\end{tabular}

Um aspecto importante a frisar na Tabela 2 é que houve um aumento no número de incidência dos itens "Combinação de negócios", "Goodwill”, "Instrumentos Financeiros", "Intangíveis e Planos de Pensão" ao longo dos sete anos. O item "Combinação de Negócios" teve o maior aumento de incidência, variando em $230 \%$ de 2000 para 2006. Os demais itens não tiveram aumentos tão significativos em suas quantidades, ao longo dos anos. Chama a atenção nessa tabela, que as diferenças têm crescido, uma vez que os ajustes no PL ou mantiveram a mesma quantidade ou avolumaram-se no período de 7 anos.

Em termos monetários, a Tabela 3 apresenta o total de ampliações ou reduções no resultado do período das empresas da amostra. 
Tabela 3 - Montante dos ajustes no LLE de 2000 a 2006 - BRGAAP x USGAAP

\begin{tabular}{|c|c|c|c|c|c|c|c|c|c|}
\hline Empresas & Perdigão & Ambev & Vivo & Braskem & Sabesp & Copel & BrasilTelS.A & BrasilTelPart & Ultrapar \\
\hline Itens & \multicolumn{9}{|c|}{ EM MILHÕES DE RS } \\
\hline Ações em Tesouraria & - & - & - & - & - & -1 & - & - & 4,3 \\
\hline $\begin{array}{l}\text { Arrendamento } \\
\text { Mercantil }\end{array}$ & - & - & $-3,8$ & - & 6,4 & - & $-4,9$ & $-4,9$ & \\
\hline Ativos Fixos & 4,8 & $-5,9$ & 132,6 & $-46,5$ & 852,9 & $-12,3$ & 924,1 & $1.015,0$ & 73,7 \\
\hline $\begin{array}{l}\text { Combinação de } \\
\text { Negócios }\end{array}$ & 11,8 & $3.691,4$ & $-644,7$ & $1.043,8$ & - & $-41,0$ & $-512,0$ & $-301,6$ & $-61,3$ \\
\hline Consolidação & $-0,2$ & $-49,4$ & 12,6 & $-37,2$ & - & 20,4 & $-7,7$ & $-629,0$ & - \\
\hline Correção Monetária & $-35,7$ & $-302,8$ & $-50,8$ & $-216,5$ & $-1.443,1$ & $-1.004,1$ & - & - & $-32,9$ \\
\hline Diferenças Cambiais & - & $-172,8$ & - & - & - & - & - & - & $-0,1$ \\
\hline Dividendos & - & - & - & - & - & - & $-36,2$ & $-46,9$ & - \\
\hline Goodwill & - & - & 789,5 & 330,6 & - & 22,8 & 578,2 & 579,6 & 25,7 \\
\hline $\begin{array}{l}\text { Imp Dif/Part } \\
\text { minoritárias }\end{array}$ & 24,1 & 169,0 & 435,3 & $-125,5$ & 403,9 & 555,2 & $-463,0$ & $-747,0$ & $-22,8$ \\
\hline Imposto Diferido & - & 7,3 & 27,9 & - & $-0,3$ & $-1,0$ & $-220,6$ & $-264,4$ & - \\
\hline $\begin{array}{l}\text { Instrumentos } \\
\text { Financeiros } \\
\end{array}$ & $-1,0$ & $-38,3$ & 68,9 & - & 11,4 & & 3,8 & 3,8 & $-1,2$ \\
\hline Intangíveis & $-27,3$ & $-58,2$ & $-838,3$ & $-107,8$ & 32,3 & $-429,0$ & $-78,0$ & $-165,5$ & $-59,4$ \\
\hline Investimento & - & 44,0 & 44,5 & $-216,7$ & - & $-1,4$ & - & - & 20,7 \\
\hline Planos de Pensão & - & 185,3 & $-11,0$ & $-105,3$ & \begin{tabular}{|l|}
$-1.025,8$ \\
\end{tabular} & $-182,4$ & 728,2 & 840,6 & - \\
\hline Provisão & - & - & - & - & 38,0 & - & $-90,2$ & $-2,6$ & $-10,2$ \\
\hline Outros & 0,1 & 171,5 & 57,3 & 185,7 & $-26,6$ & 20,6 & 555,3 & 497,2 & \\
\hline
\end{tabular}

Em termos monetários, ressalta-se que as empresas AMBEV, SABESP, COPEL e Brasil Telecom S/A foram as que tiveram ajustes mais significativos em seus lucros. Dessas, notase que, para a SABESP e a COPEL, ambas com redução de seus lucros no período, o item que mais influenciou esta redução foi a Correção Monetária que se refere ao reajuste inflacionário.

A elevação no lucro ou no prejuízo da AMBEV pode ser explicada, principalmente, pelos ajustes referentes às diferentes práticas para as Combinações de Negócios realizados no período.

No caso da Brasil Telecom S/A, não é possível apontar um único item como responsável pelo aumento do seu lucro. Contudo, salienta-se que os itens "Ativos Fixos", "Goodwill" e "Planos de Pensão" elevaram o lucro da empresa, enquanto os itens “Combinação de Negócios" e "Impostos Diferidos” reduziram seu lucro no período.

Acentua-se, ainda, que, em valores monetários, as empresas Perdigão e Ultrapar foram as que menos alterações provocaram em seus lucros, ao ajustar-se para os USGAAP. Contudo, na análise da Tabela 3, uma limitação deve ser levada em conta, qual seja, a não conversão dos números de forma completa, considerando que nenhum contato foi estabelecido com as empresas. Assim, para os números divulgados em dólares, usou-se o dólar do final do período para a conversão em reais. Adicionalmente, o efeito inflacionário também não foi levado em conta, em função de ter como objetivo somente o destaque dos ajustes em cada ano e não seu efeito acumulativo.

A Tabela 4 mostra os ajustes no resultado do ano de 2006. 
Tabela 4 - Montante dos Ajustes no LLE 2006 - BRGAAP x USGAAP

\begin{tabular}{|c|c|c|c|c|c|c|c|c|c|c|}
\hline Lucro Líquido 2006 & Perdigão & Ambev & Vivo & Braskem & Sabesp & Copel & $\begin{array}{l}\text { Brasil } \\
\text { TelS.A }\end{array}$ & \begin{tabular}{|l|} 
Brasil \\
TelPart \\
\end{tabular} & Ultrapar & Total \\
\hline Ações em Tesouraria & - & - & - & - & - & - & - & - & 0,8 & 0,8 \\
\hline Arrendamento Mercantil & - & - & $-6,8$ & - & 7,0 & - & $-4,4$ & $-4,4$ & - & $-8,6$ \\
\hline Ativos Fixos & 0,5 & $-0,8$ & 6,9 & $-38,7$ & 118,3 & 31,0 & 110,9 & 130,4 & 2,8 & 361,3 \\
\hline Comb. de Negócios & $-1,6$ & $1.227,2$ & $-757,5$ & - & & 12,9 & $-19,5$ & 23,7 & 4,0 & 489,2 \\
\hline Consolidação & $-0,2$ & $-2,5$ & $-0,4$ & 0,8 & & 10,4 & - & $-74,3$ & $\ldots$ & $-66,2$ \\
\hline Correção Monetária & $-4,1$ & $-13,7$ & $-4,0$ & $-28,6$ & $-193,8$ & $-2,8$ & - & - & $-3,6$ & $-250,6$ \\
\hline Diferenças Cambiais & - & 30,9 & - & - & - & - & - & - & 1,8 & 32,7 \\
\hline Dividendos & - & - & - & - & & - & - & - & - & - \\
\hline Goodwill & - & - & 129,3 & 330,6 & & 3,6 & 86,5 & 82,1 & 5,3 & 637,4 \\
\hline Imp Dif/Part. Min. & $-0,9$ & $-35,0$ & 249,4 & $-123,2$ & 71,0 & 120,8 & $-69,3$ & $-66,4$ & 2,2 & 148,6 \\
\hline Imposto Diferido & - & - & 61,8 & - & - & 0,2 & - & - & - & 62,0 \\
\hline $\begin{array}{l}\text { Instrumentos } \\
\text { Financeiros }\end{array}$ & $-0,6$ & $-9,0$ & 65,7 & - & $-2,6$ & - & $-16,7$ & $-16,7$ & 1,4 & 21,5 \\
\hline Intangíveis & 31,4 & $-39,8$ & $-228,0$ & 40,3 & 10,5 & $-390,9$ & $-13,0$ & 24,7 & $-17,6$ & $-582,4$ \\
\hline Investimento & - & $-2,3$ & - & $-56,8$ & - & 3,1 & - & - & 1,3 & $-54,7$ \\
\hline Planos de Pensão & - & 21,8 & 2,0 & $-57,9$ & $-140,2$ & $-11,7$ & 33,8 & 33,8 & - & $-118,4$ \\
\hline Provisão & - & - & - & - & - & - & 35,2 & $-2,5$ & - & 32,7 \\
\hline Outros & - & 113,6 & 29,0 & 11,9 & $-26,6$ & - & 102,2 & 36,8 & -1 & 266,9 \\
\hline
\end{tabular}

Destacam-se, na Tabela 4, dos valores apresentados, que as empresas AMBEV, VIVO e COPEL registraram os maiores montantes de ajustes, afetados, sobretudo, pelos itens Combinação de Negócios e Intangíveis.

$\mathrm{Na}$ Tabela 5, apresenta-se o total de aumentos ou reduções no patrimônio líquido das empresas da amostra. 
Tabela 5 - Montante dos Ajustes no PL de 2000 a 2006 - BRGAAP x USGAAP

\begin{tabular}{|c|c|c|c|c|c|c|c|c|c|}
\hline Empresas & Perdigão & Ambev & Vivo & Braskem & Sabesp & Copel & BrasilTelS.A & BrasilTelPart & Ultrapar \\
\hline Itens & \multicolumn{9}{|c|}{ EM MILHÕES DE REAIS } \\
\hline $\begin{array}{l}\text { Ações em } \\
\text { Tesouraria }\end{array}$ & - & - & - & 31,2 & - & - & - & - & $-32,7$ \\
\hline $\begin{array}{l}\text { Arrendamento } \\
\text { Mercantil }\end{array}$ & - & - & 84,9 & - & 5,7 & - & $-5,8$ & $-5,8$ & - \\
\hline Ativos Fixos & $-217,2$ & 69,5 & 55,7 & 819,4 & $-15.468,2$ & $-2.059,1$ & $1.458,0$ & 929,1 & $-271,8$ \\
\hline $\begin{array}{l}\text { Combinação de } \\
\text { Negócios }\end{array}$ & 50,9 & $1.181,8$ & $1.211,7$ & $-10.922,2$ & - & $-135,8$ & 469,2 & 532,3 & $-139,0$ \\
\hline Consolidação & $-0,9$ & 5,4 & $-30,8$ & 238,1 & - & 40,0 & - & $-1.343,4$ & - \\
\hline $\begin{array}{l}\text { Correção } \\
\text { Monetária }\end{array}$ & 350,2 & 435,4 & 48,2 & $3.807,7$ & $26.721,9$ & $7.441,4$ & - & 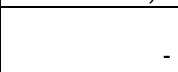 & 256,8 \\
\hline $\begin{array}{l}\text { Diferenças } \\
\text { Cambiais }\end{array}$ & - & - & - & - & - & - & - & - & - \\
\hline Dividendos & 30,4 & $1.547,9$ & 2,5 & 74,2 & - & - & 61,9 & 331,4 & - \\
\hline Goodwill & 22,6 & - & - & - & - & 86,7 & $2.929,5$ & $2.911,4$ & 81,2 \\
\hline Imposto Diferido & $-224,4$ & $-27,0$ & $-301,1$ & - & 218,8 & $-15,6$ & 8,8 & 5,2 & - \\
\hline $\begin{array}{l}\text { ImpostoDif/Part } \\
\text { Minor. }\end{array}$ & $-83,4$ & $-1.036,0$ & 21,7 & $-665,4$ & $-6.966,9$ & $-2.480,7$ & $-1.077,1$ & 349,9 & 230,9 \\
\hline $\begin{array}{l}\text { Instrumentos } \\
\text { Financeiros }\end{array}$ & 1,9 & $-234,5$ & $-93,0$ & - & 25,3 & 10,5 & 124,5 & 125,0 & $-13,3$ \\
\hline Intangíveis & - & $-1.019,4$ & - & $-2.081,6$ & $-208,4$ & 746,0 & $-581,7$ & $-570,2$ & $-485,3$ \\
\hline Investimento & 14,9 & 112,6 & $-15,6$ & $-179,5$ & - & $-181,9$ & - & - & $-82,8$ \\
\hline Planos de Pensão & - & $1.227,8$ & 42,2 & $-15,1$ & $-11.622,4$ & $1.516,4$ & $1.623,0$ & $1.574,4$ & - \\
\hline Provisão & - & - & - & & - & & $-2,7$ & $-2,7$ & 9,8 \\
\hline Outros & 2,5 & $-122,4$ & $-43,9$ & & $-1.569,2$ & $-46,0$ & $-1.424,3$ & $-1.579,4$ & - \\
\hline
\end{tabular}

Em termos monetários, acentua-se que as empresas AMBEV, BRASKEM, SABESP, COPEL, Brasil Telecom S/A e Brasil Telecom Participações foram as que tiveram ajustes mais significativos em seu patrimônio líquido.

Dessas, nota-se que, para a BRASKEM e a SABESP, ambas com redução dos valores de seu patrimônio no período, os itens que mais influenciaram tal redução foram "Combinação de Negócios" para a BRASKEM e "Ativos Fixos" para a SABESP.

$O$ aumento no patrimônio da AMBEV pode ser explicado, fundamentalmente, pelos ajustes no item "Planos de Pensão".

No caso da COPEL, o incremento do patrimônio líquido pode ser explicado, notadamente, pelos ajustes no item "Correção Monetária”.

Já para Brasil Telecom S/A e Brasil Telecom Participações, pode-se apontar o item “Goodwill” como responsável pela elevação em seu patrimônio líquido.

Destaca-se, ainda, que, em valores monetários, as empresas Perdigão e Ultrapar foram as que menos alterações provocaram em seus patrimônios, ao se ajustar para os USGAAP. Contudo, conforme mencionado na analise da Tabela 5, também existe uma limitação que deve ser levada em conta, qual seja, a não conversão dos números de forma completa, considerando que nenhum contato foi estabelecido com as empresas, bem como o não ajuste dos números pelo efeito inflacionário.

A Tabela 6 apresenta os ajustes no patrimônio líquido do ano de 2006. 
Tabela 6 - Montante de Ajustes no PL de 2006 - BRGAAP x USGAAP

\begin{tabular}{|c|c|c|c|c|c|c|c|c|c|c|}
\hline $\begin{array}{l}\text { Patrimônio } \\
\text { Líquido } 2006\end{array}$ & Perdigão & Ambev & Vivo & Braskem & Sabesp & Copel & BrasilTelS.A & BrasilTelPart & Ultrapar & Total \\
\hline \multicolumn{11}{|c|}{ EM MILHÕES DE REAIS } \\
\hline $\begin{array}{l}\text { Ações em } \\
\text { Tesouraria }\end{array}$ & - & - & - & 10,4 & - & - & - & - & $-2,1$ & 8,3 \\
\hline $\begin{array}{l}\text { Arrendamento } \\
\text { Mercantil }\end{array}$ & - & - & 21,7 & - & 6,3 & - & $-4,9$ & $-4,8$ & - & 18,3 \\
\hline Ativos Fixos & $-38,3$ & 9,3 & 43,2 & 166,7 & $-2.280,0$ & $-332,9$ & 467,8 & 422,5 & $-27,0$ & $-1.568,7$ \\
\hline $\begin{array}{l}\text { Combinação de } \\
\text { Negócios }\end{array}$ & 35,9 & $1.785,7$ & 815,8 & $-1.479,7$ & - & $-51,5$ & 120,1 & 61,3 & $-24,6$ & $1.263,0$ \\
\hline Consolidação & $-0,9$ & 6,1 & - & $-99,9$ & - & 20,5 & - & $-517,4$ & - & $-591,6$ \\
\hline $\begin{array}{l}\text { Correção } \\
\text { Monetária }\end{array}$ & 38,0 & 10,8 & 8,5 & 693,2 & $3.978,2$ & 699,6 & - & - & 24,5 & $5.452,8$ \\
\hline $\begin{array}{l}\text { Diferenças } \\
\text { Cambiais }\end{array}$ & - & - & - & - & - & - & - & - & - & 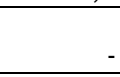 \\
\hline Dividendos & 4,2 & 65,0 & - & 18,5 & - & - & 61,9 & 36,6 & - & 186,2 \\
\hline Goodwill & - & - & - & - & - & 28,1 & $1.279,6$ & $1.316,9$ & 30,3 & $2.654,9$ \\
\hline Imp Dif/Part Min & $-26,6$ & $-143,3$ & 0,6 & $-185,7$ & $-1.301,8$ & $-409,2$ & $-405,9$ & $-125,4$ & 21,0 & $-2.576,3$ \\
\hline Imposto Diferido & $-53,9$ & - & $-47,3$ & - & $-54,9$ & $-5,2$ & - & - & - & $-161,3$ \\
\hline $\begin{array}{l}\text { Instrumentos } \\
\text { Financeiros }\end{array}$ & $-1,0$ & $-51,8$ & 2,0 & - & 11,3 & - & 3,2 & 3,7 & 14,0 & $-18,6$ \\
\hline Intangiveis & - & $-77,2$ & - & $-454,8$ & $-10,0$ & $-115,5$ & $-165,0$ & $-159,2$ & $-96,9$ & $-1.078,6$ \\
\hline Investimento & 4,5 & 20,0 & - & - & - & $-52,2$ & - & - & 1,0 & $-26,7$ \\
\hline Planos de Pensão & - & 337,4 & 43,9 & $-11,6$ & $-1.989,2$ & 947,2 & 221,1 & 172,5 & - & $-278,7$ \\
\hline Provisão & - & - & - & - & - & - & $-2,6$ & $-2,6$ & $-0,8$ & $-6,0$ \\
\hline Outros & - & $-122,4$ & $-37,3$ & - & $-80,3$ & - & - & $-91,3$ & - & $-331,3$ \\
\hline
\end{tabular}

Chama atenção, na Tabela 6, que as empresas AMBEV, BRASKEM e Brasil Telecom $\mathrm{S} / \mathrm{A}$ apresentaram os maiores montantes de ajustes, afetados, essencialmente, pelos itens "Combinação de Negócios" e "Goodwill".

Com o objetivo de analisar se houve melhoria nos níveis de comparabilidade entre os USGAAP e os BRGAAP ao longo dos anos, aplicou-se o índice de comparabilidade nos ajustes parciais de 2000 a 2006 para as 9 empresas que os divulgam conforme a classificação de UCIEDA (2003), definidos no início desta seção. Novamente, os percentuais considerados para o teste de materialidade foram $5 \%$ e $10 \%$. Os resultados estão expostos nas Tabelas 7 e 8. 
Tabela 7 - Número de Ajustes no Lucro Líquido para o ano de 2000 classificados entre 5\% e 10\% de materialidade

\begin{tabular}{|c|c|c|c|c|c|c|c|c|}
\hline 2000 & - & \begin{tabular}{|l}
$(0,90-$ \\
$0,95]$
\end{tabular} & $\begin{array}{l}(0,95- \\
1,05)\end{array}$ & $\begin{array}{l}{[1,05-} \\
1,10)\end{array}$ & {$[1,10-$} & Total & $\begin{array}{l}\text { \%Ajustes } \\
\text { Material 5\% }\end{array}$ & $\begin{array}{l}\text { \%Ajustes } \\
\text { Material 10\% }\end{array}$ \\
\hline Ações em Tesouraria & - & - & 1 & - & - & 1 & $100,0 \%$ & $100,0 \%$ \\
\hline $\begin{array}{l}\text { Arrendamento } \\
\text { Mercantil }\end{array}$ & - & - & - & - & - & - & - & - \\
\hline Ativos Fixos & 1 & - & 8 & 1 & - & 10 & $42,1 \%$ & $52,6 \%$ \\
\hline $\begin{array}{ll}\text { Combinação } & \text { de } \\
\text { Negócios } & \\
\end{array}$ & 1 & - & 1 & 2 & - & 4 & $11,1 \%$ & $44,4 \%$ \\
\hline Consolidação & - & - & 1 & 1 & - & 2 & $20,0 \%$ & $40,0 \%$ \\
\hline Correção monetária & - & 1 & 2 & 2 & - & 5 & $20,0 \%$ & $50,0 \%$ \\
\hline Diferenças Cambiais & - & - & 1 & - & - & 1 & $100,0 \%$ & $100,0 \%$ \\
\hline Dividendos & - & - & - & - & - & 0 & - & - \\
\hline Goodwill & - & - & 1 & - & - & 1 & $25,0 \%$ & $25,0 \%$ \\
\hline $\begin{array}{l}\operatorname{Imp} \text { Dif/Part } \\
\text { Minoritárias }\end{array}$ & - & 3 & 4 & - & - & 7 & $50,0 \%$ & $87,5 \%$ \\
\hline Imposto Diferido & - & - & 2 & 1 & 1 & 4 & $33,3 \%$ & $66,7 \%$ \\
\hline $\begin{array}{l}\text { Instrumentos } \\
\text { Financeiros }\end{array}$ & - & - & 1 & - & - & 1 & $50,0 \%$ & $50,0 \%$ \\
\hline Intangíveis & - & 2 & 2 & 1 & - & 5 & $28,6 \%$ & $71,4 \%$ \\
\hline Investimento & - & - & - & 1 & - & 1 & - & $50,0 \%$ \\
\hline Planos de Pensão & - & 1 & 5 & 2 & - & 8 & $27,8 \%$ & $44,4 \%$ \\
\hline Provisão & - & - & 1 & - & - & 1 & $100,0 \%$ & $100,0 \%$ \\
\hline Outros & - & - & 1 & - & - & 1 & $14,3 \%$ & $14,3 \%$ \\
\hline Total $=101$ & 2 & 7 & 31 & 11 & 1 & 52 & $30,7 \%$ & $51,5 \%$ \\
\hline
\end{tabular}

Os itens “Ações em Tesouraria”, “Diferenças Cambiais" e "Provisão" atingiram 100\% em um nível de materialidade a $5 \%$. Isso acontece porque o índice de comparabilidade, para esses itens de todas as empresas da amostra, localizou-se entre 0,95 e 1,05. Por sua vez, 42,1\% dos ajustes referentes a "Ativos Fixos" ficaram entre 0,95 e 1,05 em um nível de materialidade de $5 \%$, e, em torno de $52,6 \%$ dos ajustes, localizaram-se na faixa de 0,90 e 1,10, quando avaliados a $10 \%$ de materialidade. No total dos 101 ajustes do ano de 2000, $30,7 \%$ dos itens foram comparáveis a $5 \%$ e $51,5 \%$ foram comparáveis a $10 \%$.

A Tabela 8 apresenta os índices parciais de cada item calculado para todas as empresas da amostra para o ano de 2006. 
Tabela 8 - Número de Ajustes no Lucro Liquido para o ano de 2006 classificados entre 5\% e 10\% de materialidade

\begin{tabular}{|l|c|c|c|c|c|c|c|c|}
\multicolumn{1}{c|}{2006} & $(0,90-$ & $(0,95-$ & {$[1,05-$} & & & \%Ajustes & $\%$ Ajustes \\
& $-0,90$ & $0,95]$ & $1,05)$ & $1,10)$ & {$[1,10-$} & Total & Material 5\% & Material 10\% \\
\hline Ações em Tesouraria & - & - & 1 & - & - & 1 & $100,0 \%$ & $100,0 \%$ \\
\hline Arrendamento Mercantil & - & - & 4 & - & - & 4 & $100,0 \%$ & $100,0 \%$ \\
\hline Ativos Fixos & 1 & 3 & 11 & 1 & - & 16 & $57,9 \%$ & $84,0 \%$ \\
\hline Combinação de Negócios & - & - & 16 & 1 & - & 17 & $76,2 \%$ & $81,0 \%$ \\
\hline Consolidação & - & - & 6 & - & - & 6 & $85,7 \%$ & $85,7 \%$ \\
\hline Correção monetária & - & - & 7 & - & 1 & 8 & $63,6 \%$ & $72,7 \%$ \\
\hline Diferenças Cambiais & - & - & 2 & - & - & 2 & $100,0 \%$ & $100,0 \%$ \\
\hline Dividendos & - & - & - & - & - & - & - & - \\
\hline Goodwill & - & 2 & 11 & - & 1 & 14 & $68,8 \%$ & $87,5 \%$ \\
\hline Imp Dif/Part Minoritárias & - & - & 11 & - & 3 & 14 & $64,7 \%$ & $82,4 \%$ \\
\hline Imposto Diferido & - & - & 1 & - & - & 1 & $50,0 \%$ & $50,0 \%$ \\
\hline Instrumentos Financeiros & - & - & 6 & - & - & 6 & $85,7 \%$ & $85,7 \%$ \\
\hline Intangíveis & - & 2 & 14 & - & - & 16 & $58,3 \%$ & $66,6 \%$ \\
\hline Investimento & - & - & 3 & - & 1 & 3 & $75,0 \%$ & $100,0 \%$ \\
\hline Planos de Pensão & 2 & - & 12 & - & - & 14 & $75,0 \%$ & $87,5 \%$ \\
\hline Provisão & - & 1 & 3 & - & - & 4 & $75,0 \%$ & $100,0 \%$ \\
\hline Outros & - & 3 & 4 & - & - & 7 & $50,0 \%$ & $87,5 \%$ \\
\hline Total = 163 & 3 & 11 & 112 & 2 & 4 & 134 & $68,7 \%$ & $82,2 \%$ \\
\end{tabular}

Observa-se, na Tabela 8, que os itens "Ações em Tesouraria”, “Arrendamento Mercantil" e "Diferenças Cambiais" atingiram 100\% em um nível de materialidade a $5 \%$. Isso foi consequiência do índice de comparabilidade para esses itens se localizarem entre 0,95 e 1,05 . Por sua vez, $75 \%$ dos ajustes referentes a "Planos de Pensão" ficaram entre 0,95 e 1,05 em um nível de materialidade de $5 \%$ e, em torno de $87,5 \%$ dos ajustes, estabeleceram-se na faixa de 0,90 e 1,10 , quando avaliados a $10 \%$ de materialidade. No total dos 163 ajustes do ano de 2006, 68,7\% dos itens foram comparáveis a $5 \%$ e $82,2 \%$ foram comparáveis a $10 \%$.

$\mathrm{Na}$ Tabela 9, são registrados os índices de comparabilidade para as 28 empresas da amostra para os anos de 2000 e 2006.

Tabela 9 - Frequiência de valores do índice de comparabilidade no lucro líquido

\begin{tabular}{|l|c|c|c|c|c|}
\hline Nível de Materialidade & Valores índices & 2000 & Percentual & 2006 & Percentual \\
\hline $5 \%$ de Materialidade & $0,95-1,05$ & 5 & $17,86 \%$ & 5 & $17,86 \%$ \\
\hline $10 \%$ de Materialidade & $0,90-1,10$ & 7 & $25 \%$ & 7 & $25 \%$ \\
\hline$<5 \%$ e $>10 \%$ de Materialidade & $<0,90$ e $>1,10$ & 21 & $75 \%$ & 21 & $75 \%$ \\
\hline Total de empresas & & 28 & & 28 &
\end{tabular}

A Tabela 9 mostra que, no ano de 2000 , a maior parte das empresas ( 21 em 28) não demonstrou materialidade a $5 \%$ e a $10 \%$. 0 mesmo se repetiu em 2006, quando 21 das 28 empresas não apresentaram materialidade a $5 \%$ e a $10 \%$.

Por outro lado, em um nível de materialidade de 5\%, vê-se, na Tabela 9, que 17,86\% das empresas tiveram seus lucros comparáveis em 2000 e em 2006. A 10\% de materialidade 
25\% das empresas em 2000 e em 2006, das empresas publicaram lucros comparáveis em BRGAAP e USGAAP.

Esses resultados das 28 empresas são incompatíveis com os índices parciais dos mesmos anos das 9 empresas quando se observou uma melhoria no nível de comparabilidade divulgado pelas empresas.

\section{CONSIDERAÇÕES FINAIS}

Este trabalho teve por objetivo analisar o nível de comparabilidade das empresas brasileiras que apuram seus resultados de acordo com os USGAAP, por meio da identificação e tratamento dos principais ajustes no lucro e no patrimônio líquido entre as demonstrações contábeis, de acordo com os dois conjuntos de normas no período de 2000 a 2006. Ele se desenvolveu nas seguintes etapas: quantificação dos ajustes nas demonstrações contábeis de 2000 a 2006; identificação monetária dos ajustes de 2000 a 2006; apuração do nível de comparabilidade entre os ajustes parciais de 2000 e 2006; e entre os lucros divulgados de 2000 e 2006.

Inicialmente, foi demonstrado o total de ajustes ocorridos no lucro líquido e no patrimônio líquido das 9 empresas pesquisadas, concluindo-se que houve variações de 30\% e até mesmo de $200 \%$, de 2000 para 2006, em alguns itens.

Pela identificação monetária dos ajustes, foi enfatizado o total de aumentos ou reduções no resultado e no patrimônio líquido do período das empresas da amostra, podendo-se citar as empresas AMBEV, SABESP, COPEL e Brasil Telecom S.A como as que tiveram ajustes mais significativos em seus lucros, e as empresas AMBEV, BRASKEM, SABESP, COPEL, Brasil Telecom S.A e Brasil Telecom Participações como as que tiveram ajustes mais significativos em seu patrimônio líquido.

Por meio da apuração do nível de comparabilidade entre os ajustes, foi possível detectar uma melhoria no nível de comparabilidade divulgado pelas empresas, sendo que, em $2000,51,5 \%$ dos ajustes foram comparáveis a $10 \%$ e, em $2006,86,5 \%$ foram comparáveis a $10 \%$. A $5 \%$ de materialidade $30,7 \%$ dos ajustes foram comparáveis em 2000 e $72,3 \%$ em 2006. Por outro lado, observando o nível de comparabilidade entre os lucros, conclui-se que não houve melhoria da comparabilidade de 2000 para 2006, mostrando incompatibilidade com os ajustes parciais divulgados pelas empresas ao longo dos 7 anos.

Os resultados do presente estudo demonstram que as empresas brasileiras que se reportaram em USGAAP, no período de 2000 a 2006, em sua maior parte, não tiveram seus lucros comparáveis a $5 \%$ e $10 \%$ de materialidade, resultando em mensurações materialmente diferentes do lucro/prejuízo líquido apurado segundo os BRGAAP e os USGAAP. Contudo, o presente estudo possibilitou uma verificação da falta de informações comparáveis entre USGAAP e BRGAAP. Portanto, muito se deve evoluir para conseguir-se atingir demonstrações mais comparáveis entre si e, assim, assegurar a comparabilidade das informações prestadas por diferentes países e, consequentemente, uma base única para a decisão dos investidores. 


\section{REFERÊNCIAS}

ADAMS, C. A.; WEETMAN, P. E.; JONES, A. E.; GRAY, S. J. Reducing the burden of U.S.GAAP reconciliations by foreign companies listed in the United States: The Key question of materiality. The European Accounting Review. v. 8, 3, p. 1-22, 1999.

CARVALHO, L. Nelson G.; LEMES, Sirlei; COSTA, Fábio M. da. Contabilidade internacional: aplicação das IFRS 2005. São Paulo: Atlas, 2006.

CASTRO NETO, José Luis de. Contribuição ao estudo da prática harmonizada da contabilidade da União Européia. 1998. 232f. Tese (doutorado em Ciências Contábeis) Curso de Pós-Graduação em Contabilidade e Controladoria, Faculdade de Economia, Administração e Contabilidade, Universidade de São Paulo, São Paulo, 1998.

GIL, Antonio Carlos. Como elaborar projetos de pesquisa. 4.ed. São Paulo: Atlas, 2002.

GRAY, S. J. The impact of international accounting differences from a security-analysts perspective: Some European evidence. Journal of Accounting Research, 18, p.64-76, 1980.

HAVERTY, John L. Are IFRS and USGAAP converging? Some evidence from People's Republic of China companies listed don the New York Stock Exchange. Journal of International Accounting Auditing e Taxation, United States, v.15, p. 48-71, 2006.

IASB, International Financial Reporting Standards (IFRSs). IAS UK: IASCF; 2008.

LOPES, Alexsandro B, MARTINS, Eliseu. Teoria da contabilidade: uma nova abordagem. São Paulo: Atlas, 2005.

MARTINS, Gilberto de Andrade; THEÓPHILO, Carlos Renato. Metodologia da investigação científica para ciências sociais aplicadas. São Paulo: Atlas, 2007.

NIYAMA, Jorge K. Contabilidade Internacional. São Paulo: Atlas, 2005.

PRICEWATERHOUSECOOPERS. Demonstrações Financeiras e Sinopse Legislativa. 2004.

UCIEDA, Jose Luis. A Decade of Reconciliation to USGAAP What Have We Learned? Spanish Journal of Finance and Accounting. Spanish, 115, p. 69-115, April 2003.

WEETMAN, P, JONES, E. A. E, ADAMS, C. A, GRAY, S. J. Profit Measurement and UK Accounting Standards: A Case of Increasing Disharmony in Reletion to USGAAP and IASs. Accounting and Business Research,. v. 28, 3, p. 189-208, 1998. 